\title{
SPONTANEOUS TRANSVAGINAL SMALL BOWEL EVISCERATION: A CASE REPORT
}

doi: $10.1590 / \mathrm{S} 1807-59322010000500015$

Rogério Serafim Parra, José Joaquim Ribeiro da Rocha, Omar Feres

\section{INTRODUCTION}

Spontaneous evisceration through the vagina was first described in 1907 by McGregor. ${ }^{1}$ To date, only eighty-five cases of transvaginal small bowel evisceration have been documented worldwide. ${ }^{1,2}$ The primary risk groups for spontaneous vaginal evisceration include postmenopausal women, ${ }^{1,3-7}$ vaginal surgery cases, ${ }^{1,8-10}$ multiparae,,${ }^{11}$ and women of older age., ${ }^{2,3}$

In postmenopausal woman, transvaginal evisceration is frequently associated with increased abdominal pressure, ${ }^{1}$ vaginal ulceration due to severe atrophy, and straining at stool. ${ }^{6,8}$

Vaginal evisceration is a medical emergency that requires prompt recognition and immediate surgical intervention. ${ }^{1}$ The associated mortality rate is 5.6 percent; however, the incidence of morbidity is higher ${ }^{3,8}$ when the bowel has become strangulated through the vaginal defect.

Here, we report a case of vaginal vault rupture with evisceration through the vagina and highlight the risk factors, clinical presentation, and treatment options for this rare gynecological emergency.

\section{CASE REPORT}

A female patient aged seventy-five years was admitted to the emergency room with abdominal pain ten days after an angioplasty plus coronary stent implantation, which had been performed through the femoral artery. Three days after the angioplasty; i.e., one week prior to presentation to the emergency room, an inguinal hematoma developed as complication of the femoral arteriography had to be

Division of Coloproctology, Department of Surgery and Anatomy, School of Medicine of the University of São Paulo - Ribeirão Preto/SP, Brazil. Email: rogeriosparra@gmail.com Tel: 5516 3621-1122 drained. Thereafter, the patient suffered from constipation and had difficulties with evacuation. On the day the woman presented to the emergency room, she felt a sudden and dull abdominal discomfort during evacuation and noticed a loop of bowel protruding from her vagina. There was no history of abdominal or vaginal trauma.

Thirty years prior to the present admission, the woman had undergone a total abdominal hysterectomy for a benign pathology. The operation had no complications, and the patient's recovery was uneventful. After the hysterectomy and ten and twelve years prior to the present admission, the woman had undergone two perinea surgeries for a prolapsed bladder. Apart from these three surgeries, the she had no past medical or gynecological history worthy of note.

Upon admission to the emergency room, the patient's blood pressure was $110 \times 70 \mathrm{mmHg}$, her heart rate was 88 bpm, and an abdominal examination indicated significant pain. The pelvic examination revealed $40 \mathrm{~cm}$ of small bowel prolapsing through her vagina (Figure 1). After resuscitation of the patient, she received intravenous broad-spectrum antibiotics ( $1 \mathrm{~g}$ of Ceftriaxon and $500 \mathrm{mg}$ of Metronidazole),

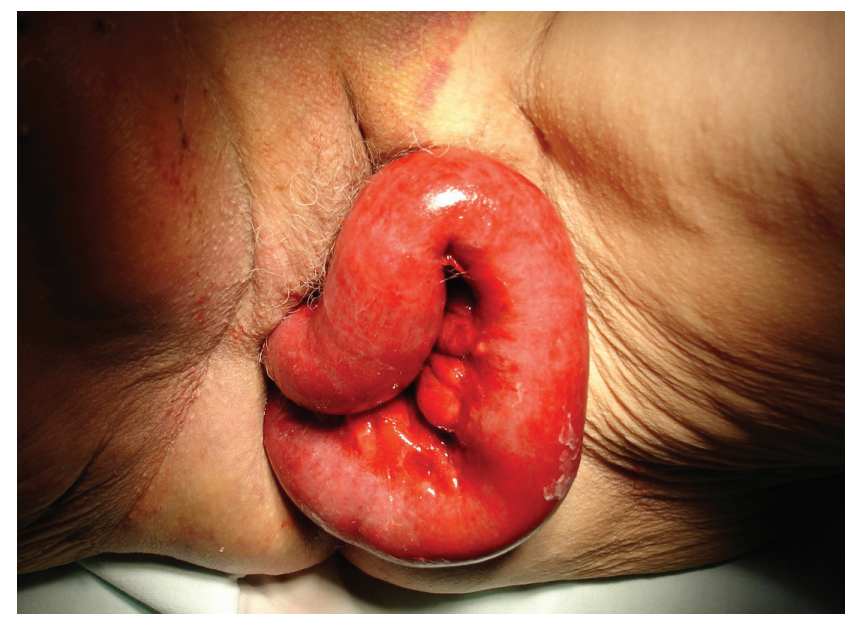

Figure 1 - Pelvic examination revealing the small bowel prolapsing through the vagina. 
and her bowel was wrapped with warm, sterile, and salinesoaked gauze for transfer to the operating room. There, under rachianesthesia, the woman was placed in lithotomy position, so that the viability of her small bowel could be assessed. The examination revealed that the bowel was edematous and thick-walled, but still viable. There was no evidence of necrosis. The inguinal hematoma, which looked infected, was drained (Figure 2). The patient was then placed in the Trendelenburg position. Because the vault defect was located high in the vagina, all attempts to transvaginally reduce the small bowel into the peritoneal cavity were unsuccessful. Consequently, a midline subumbilical incision was made, and the prolapsed bowel was reduced into the abdomen and inspected for damage throughout its length. Thereafter, the vaginal vault defect was closed with absorbable sutures (Polygleprone 2.0) by a vaginal route (Figure 3), and a 30-cm segment of bowel was excised. Although the bowel was viable, we decided to carry out this procedure because there was an expansible hematoma in the mesum. Broad-spectrum antibiotics were postoperatively given for six days. The patient had no postoperative complications and was discharged from the hospital after six days. In a follow-up examination three months later, the woman exhibited no evidence of recurrence, and the vaginal vault had healed satisfactorily.

\section{DISCUSSION}

Vaginal evisceration is a rare event that has been reported to occur after vaginal traumas induced by coitus, obstetric instrumentation, and the insertion of foreign

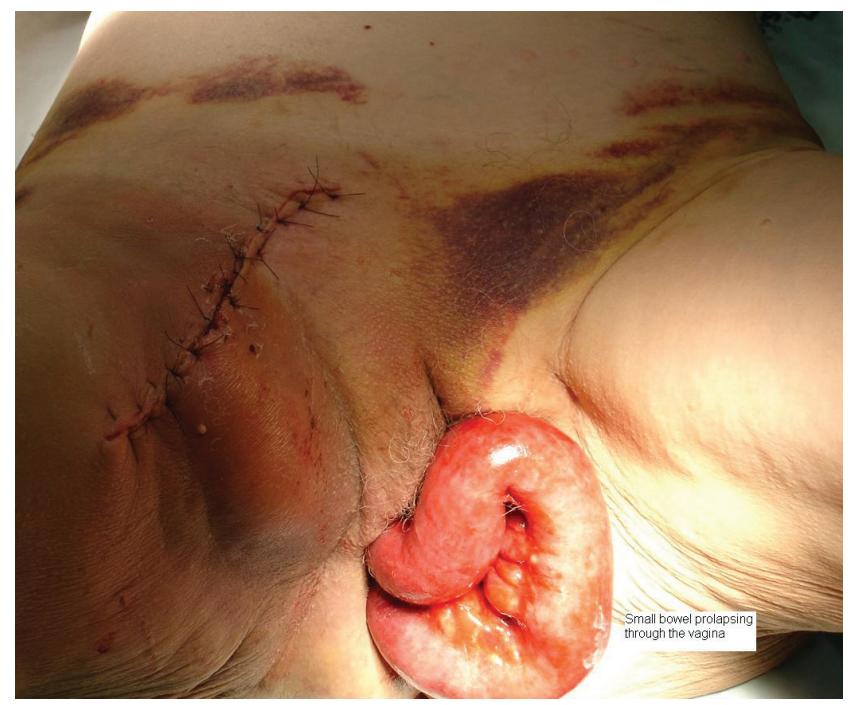

Figure 2 - The pelvic examination revealed that the small bowel was edematous and thick-walled, but still viable. The inguinal hematoma was drained for a second time, specifically at the time of the prolapse surgery, because it looked infected.

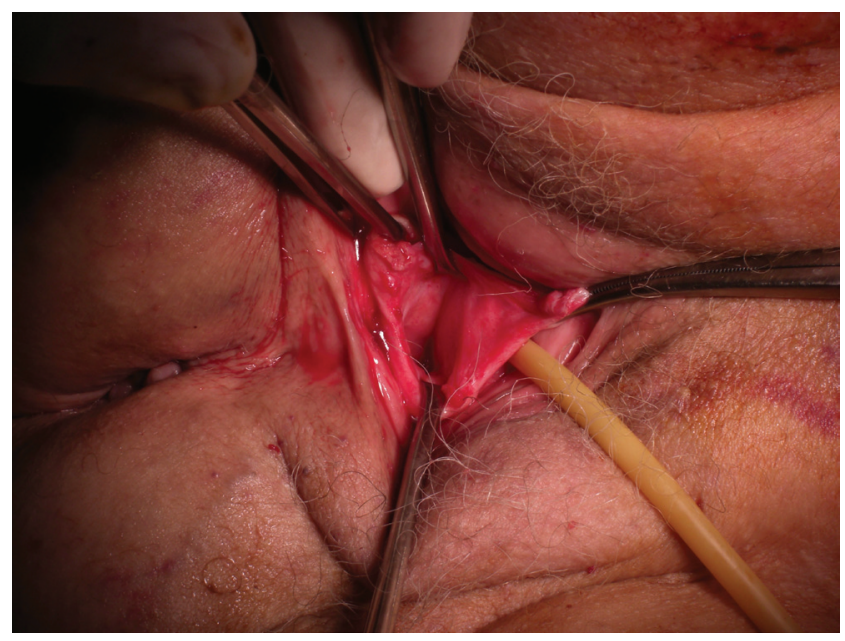

Figure 3 - The vaginal defect was closed by absorbable sutures via the vaginal route.

bodies. Vaginal evisceration has also been reported after pelvic surgery and in patients with enterocele. ${ }^{8}$ The risk groups for transvaginal small bowel evisceration include the elderly; postmenopausal women; ${ }^{2,7}$ female patients after vaginal, ${ }^{9,10,12}$ abdominal, ${ }^{4-6,13}$ or laparoscopic hysterectomy; ${ }^{14}$ and multiparous women. ${ }^{11}$ Due to the weakening of vaginal tissue caused by genital atrophies and enteroceles, the risk of spontaneous evisceration is increased in postmenopausal women, particularly in combination with straining at stool and/or vaginal ulceration. ${ }^{8,15}$ Because the postmenopausal vagina is thin, scarred, foreshortened, and has diminished vascularity, it is more prone to rupture. ${ }^{1,4}$ In postmenopausal women, vaginal ruptures most commonly occur at the posterior fornix. ${ }^{8,16}$

In postmenopausal women, evisceration can occur either spontaneously or, more frequently, in connection with an increase in intra-abdominal pressure induced by coughing, defecating, or falling. ${ }^{11}$ In premenopausal patients, evisceration is usually preceded by vaginal trauma caused by rape, coitus, obstetric instrumentation, or the insertion of foreign bodies. ${ }^{1,3,8,16}$ Additional risk factors for vaginal evisceration include previous vaginal surgeries and enteroceles. ${ }^{8}$ According to Kowalski et $a l .{ }^{2}, 73$ percent of patients with vaginal evisceration had previously undergone some kind of vaginal surgery, most commonly transvaginal hysterectomies or enterocele repairs. In 63 percent of the reported cases, the patients had enteroceles, which putatively caused further stretching of the atrophic vagina, thus making it more susceptible to rupture. Of all the eighty-five cases of vaginal evisceration reported in the literature to date, ${ }^{8}$ 50-75 percent of the patients had undergone one or more previous vaginal operations, ${ }^{3,8}$ and roughly 25 percent of the eviscerations occurred after abdominal hysterectomy. ${ }^{2}$ Postoperative cuff infections after hysterectomy have also 
been shown to contribute to evisceration. ${ }^{13}$ So far, there are no reported cases of vaginal vault rupture and evisceration due to perineal proctectomy or rectal prolapse.

In the present case, one of the underlying causes of the evisceration was probably the fact that the patient was a postmenopausal woman with previous history of pelvic surgeries (hysterectomy and perinioplasty), which putatively had weakened her pelvic floor and consequently contributed to the vaginal rupture. A second cause for the evisceration was excessive strain due to the difficulty in evacuating in the presence of a retroperitoneal hematoma.

Vaginal evisceration is a surgical emergency, and immediate recognition and surgical repair are crucial for its successful management. The appropriate management of evisceration includes a thorough assessment of the herniated viscus and surgical repair of the vaginal defect. In cases where the eviscerated bowel is viable and can be reduced into the peritoneal cavity without complication, the closure of the vaginal defect can be accomplished by a vaginal approach $;{ }^{2}$ however, in patients with minimal or no enterocele, the vaginal defect may be located high in the vagina, as was the case in the present study. Under these circumstances, a vaginal approach is not viable because the bowel, which becomes trapped and strangulated after protruding through the defect, prevents access to the defect itself. In these cases, laparotomy is necessary to access the defect, reduce the bowel into the abdomen, and resect any nonviable bowel. To date, all the reported cases that have required bowel resection have been managed with exploratory laparotomy followed by repair of the vaginal defect. ${ }^{2,17}$ A combined abdominal and vaginal surgical approach, as the one used in the present case report, is recommended for adequate evaluation and effective repair of the tissues involved. ${ }^{11}$

\section{REFERENCES}

1. Yuce K, Dursun P, Gultekin M. Posthysterectomy intestinal prolapse after coitus and vaginal repair. Arch Gynecol Obstet. 2005;272:80-1.

2. O'Brien LM, Bellin LS, Isenberg GA, Goldstein SD. Spontaneous transvaginal small-bowel evisceration after perineal proctectomy: report of a case and review of the literature. Dis Colon Rectum. 2002;45:698-9.

3. Kowalski LD, Seski JC, Timmins PF, Kanbour AI, Kunschner AJ, Kanbour-Shakir A. Vaginal evisceration: presentation and management in postmenopausal women. J Am Coll Surg. 1996;183:225-9.

4. Rajesh S, Kalu E, Bong J, Wales N. Evisceration 5 years post abdominal hysterectomy. J Obstet Gynaecol Res. 2008;34:425-7.

5. Powell JL. Vaginal evisceration following vaginal hysterectomy. Am J Obstet Gynecol. 1973;115:276-7.

6. Feiner B, Lissak A, Kedar R, Lefel O, Lavie O. Vaginal evisceration long after vaginal hysterectomy. Obstet Gynecol. 2003;101:1058-9.

7. Ramirez PT, Klemer DP. Vaginal evisceration after hysterectomy: a literature review. Obstet Gynecol Surv. 2002;57:462-7.

8. Moen MD, Desai M, Sulkowski R. Vaginal evisceration managed by transvaginal bowel resection and vaginal repair. Int Urogynecol J. 2003;14:218-20.

9. Brehm V, Steenvoorde P, Oskam J. Vaginal evisceration of small-bowel loops following prior vaginal hysterectomy: a graciloplasty performed to reconstruct the rectovaginal septum. Int J Surg. 2008;6:34-5.
10. Patravali N, Kulkarni T. Bowel evisceration through the vaginal vault: a delayed complication following hysterectomy. J Obstet Gynaecol. 2007;27:211.

11. Rollinson D, Brodman ML, Friedman F Jr, Sperling R. Transvaginal small-bowel evisceration: a case report. Mt Sinai J Med. 1995;62:235-8.

12. Partsinevelos GA, Rodolakis A, Athanasiou S, Antsaklis A. Vaginal evisceration after hysterectomy: a rare condition a gynecologist should be familiar with. Arch Gynecol Obstet. 2009;279:267-70.

13. Somkuti SG, Vieta PA, Daugherty JF, Hartley LW, Blackmon EB Jr. Transvaginal evisceration after hysterectomy in premenopausal women: a presentation of three cases. Am J Obstet Gynecol. 1994;171:567-8.

14. Thomson AJ, Elbiss HE. Re: Vaginal evisceration following total laparoscopic hysterectomy: case report and review of the literature. Aust N Z J Obstet Gynaecol. 2002;48:447-8.

15. Guttman A, Afilalo M. Vaginal evisceration. Am J Emerg Med. 1990;8:127-8.

16. Kambouris AA, Drukker BH, Barron J. Vaginal evisceration. Arch Surg. 1981;116:949-51.

17. Ho PW, Lee CW. Transvaginal small bowel evisceration and strangulation. ANZ J Surg. 2008;78:726-7. 